\title{
Introduction to the Minitrack on Collaboration via Social Media
}

\author{
Margeret Hall \\ University of Nebraska at \\ Omaha \\ mahall@unomaha.edu
}

\author{
Douglas C. Derrick \\ University of Nebraska at \\ Omaha \\ dcderrick@unomaha.edu
}

\author{
Athanasios Mazarakis \\ Kiel University \\ A.Mazarakis@zbw.eu
}

\begin{abstract}
Collaborative via Social Media 2019 kicks off its inaugural year by introducing three impactful new articles discussing dimensions of social media's facilitating role in group processes. This short article sets the stage for the minitrack, introduces the papers, and concludes with areas of future interest. Looking ahead to Collaboration via Social Media 2020, we introduce potential topics for further research.
\end{abstract}

\section{Introduction to Minitrack}

Successful collaboration is often difficult and yet interactions on social media are accessible, pervasive, varied, and impactful [8]. The role of social media as a collaboration technology and its impact of the effectiveness and overall success of collaboration is a current and ongoing research gap $[6,14]$. Collaboration technologies are a critical aspect of institutional and organizational processes $[12,15]$ that already face many pitfalls such distance between teams, dominance, lack of efficiency, lack of focus, overwhelming information, differing motivations, and groupthink [9]. These aspects are only heightened when artificial elements like bots or other intelligent technologies are considered [2].

The challenge for researchers and practitioners alike is understanding the impact of social media's unstructured and time-differentiated content delivery on collaborative processes, groups, and teams. This is a multi-dimensional challenge spanning technical, behavioral, social, emotional, economic, and political boundaries. This mini-track invited papers that address theoretical and practical challenges in assessing, staging, and deploying social media for collaboration within and between organizations, groups, teams, and machines, at of the key international platforms on which the following issues can be discussed. Particularly, it invited discussions of:
1. The impact of the unstructured, non-timeconstrained nature of social media interactions on collaborative efforts.

2. Theoretical aspects of social media-facilitated collaboration.

3. User studies concentrating on collaborative social media platforms such as Tumblr, Slack, Trello, wikis, and others.

4. Theoretical approaches and designs of social media enabled collaboration processes, tools, and the frontiers of current knowledge and practice.

5. Processes, interventions, and techniques that focus social media technologies on collaborative problem solving.

6. Empirical studies or case studies that examine the use of social media as collaboration technology.

7. Social media's influence on decision making and collaboration.

8. Evaluation methods and metrics for assessing performance in social media-facilitated collaborative efforts.

9. Fostering collaboration via Social Media through incentive engineering.

Further, we would like to express how grateful we are for our reviewers who supported this track in becoming what it is. We send our thanks for your support and time in these efforts.

\section{New Works in Collaboration via Social Media}

The work of Zytko, Ricken, Jones, \& Butler [17] analyzes a case study of matching strangers to activities via an app. They consider individuals' willingness to initiate activities given the overall interest in the activity. They find that when the efforts of planning do not exceed interest in activities, people can be convinced to organize events with strangers. Given recent interest in the fraying of traditional social ties, their results help to illuminate ways forward in social media facilitated social groups.

The work of Firpo, Zhang, Olfman, Sirisaengtaksin, \& Roberts [3] considers patching 
social capital on commuter institutions in higher education by way of a recommender system. Initial results suggest that this social media apps notifications' can support connecting individuals within and across their institution, supporting connection of person to place. Strong social capital in turn supports strong collaboration potential between and across students and other stakeholders.

Finally, the work of $\mathrm{Li}$, Huang, $\mathrm{He}, \& \mathrm{Xu}$ [11] considers enterprise applications for collaborative social media. Consider the differences between enterprise social media and enterprise information systems, the authors propose distinguishing enterprise social media from other adoption frameworks. Particularly given social media's predominance of use in general, special care needs to be taken in introducing enterprise versions (e.g., Workplace by Facebook) as previous experience, social influence, and the facilitating conditions must be considered to be previously-influenced variables.

\section{Moving Forward}

Social media is a reality of everyday life. More and more, social platforms and app facilitate formerly inperson only functions, like collaboration. Empirical and theoretical research on collaborative via social media has a rich future. Future topics of research should include both qualitative and quantitative approaches, including research from positivist, interpretivist, or critical perspectives as well as studies from the lab, from the field, or those developmental in nature. We encourage authors to consider the affordances of different platforms and that impact on the nature of collaboration via social media [7]. Research investigating design approaches [10], crowdoriented designs $[13,15,16]$, collaborative mechanism design $[4,5]$, and malicious behavior in collaborative spaces [1] are particularly encouraged.

\section{References}

[1] Derrick, D., Sporer, K., Church, S. and Ligon, G. 2017. Ideological rationality and violence: An exploratory study of ISIL's cyber profile. Dynamics of Asymmetric Conflict. 9, 1-3 (2017), 57-81.

[2] Derrick, D.C. and Elson, J.S. 2018. Automated leadership: Influence from embodied agents. Lecture Notes in Computer Science (including subseries Lecture Notes in Artificial Intelligence and Lecture Notes in Bioinformatics) (2018), 51-66.

[3] Firpo, D.R.T.Đ., Zhang, S., Olfman, L.,
Sirisaengtaksin, K. and Roberts, J.T. 2019. System Design for an Online Social Networking App with a Notification and Recommender System to Build Social Capital in a University Setting. HICSS'52 (2019).

[4] Haas, C., Caton, S. and Weinhardt, C. 2011. Engineering incentives in social clouds. Proceedings - 11th IEEE/ACM International Symposium on Cluster, Cloud and Grid Computing, CCGrid 2011 (2011), 572-575.

[5] Haas, C., Hall, M. and Vlasnik, S.L. 2018. Finding optimal mentor-mentee matches: A case study in applied two-sided matching. Heliyon. 4, 6 (2018), 1-17.

DOI:https://doi.org/10.1016/j.heliyon.2018.e00 634.

[6] Hall, M., Mazarakis, A., Chorley, M.J. and Caton, S. 2018. Editorial of the Special Issue on Following User Pathways: Key Contributions and Future Directions in CrossPlatform Social Media Research. International Journal of Human-Computer Interaction. 34, 10 (2018), 895-912.

DOI:https://doi.org/10.1080/10447318.2018.14 71575 .

[7] Hall, M., Mazarakis, A., Peters, I., Chorley, M., Caton, S., Mai, J.-E. and Strohmaier, M. 2016. Following user pathways: Cross platform and mixed methods analysis in social media studies. Conference on Human Factors in Computing Systems - Proceedings (2016).

[8] Housley, W., Procter, R., Edwards, A., Burnap, P., Williams, M., Sloan, L., Rana, O., Morgan, J., Voss, A. and Greenhill, A. 2014. Big and broad social data and the sociological imagination: A collaborative response. Big Data \& Society. 1, 2 (Aug. 2014), 2053951714545135. DOI:https://doi.org/10.1177/205395171454513 5.

[9] Kaschig, A., Maier, R., Sandow, A., Lazoi, M., Schmidt, A., Barnes, S.A., Bimrose, J., Brown, A., Bradley, C., Kunzmann, C. and Mazarakis, A. 2013. Organizational learning from the perspective of knowledge maturing activities. IEEE Transactions on Learning Technologies. 6, 2 (2013), 158-176.

DOI:https://doi.org/10.1109/TLT.2013.14.

[10] Krause, M. 2014. Designing Systems with Homo Ludens in the Loop. Handbook of Human Computation. P. Michelucci and K. Greene, eds. Springer New York. 393-409.

[11] Li, H., Huang, L., He, X. and Xu, Y. 2019. Driving the Use of Enterprise Social Media at Work: A Framework for Employees ' 
Adoption. HICSS'52 (2019).

[12] Lindner, A., Hall, M., Niemeyer, C. and Caton, S. 2015. BeWell: A Sentiment Aggregator for Proactive Community Management. CHI'15 Extended Abstracts (Seoul, Korea, 2015), 1055-1060.

[13] Mazarakis, A. 2015. Using gamification for technology enhanced learning: The case of feedback mechanisms. Bulletin of the Technical Committee on Learning Technology. 17, 4 (2015), 6-9.

[14] Mazarakis, A. and Bräuer, P. 2018. Gamification is working, but which one exactly? Proceedings of the Technology, Mind, and Society - TechMindSociety '18 (2018), Article 22.

[15] Niemeyer, C., Teubner, T., Hall, M. and
Weinhardt, C. 2018. The Impact of Dynamic Feedback and Personal Budgets on Arousal and Funding Behaviour in Participatory Budgeting. Group Decision and Negotiation. (2018). DOI:https://doi.org/10.1007/s10726018-9578-6.

[16] Prpić, J., Shukla, P.P., Kietzmann, J.H. and McCarthy, I.P. 2015. How to work a crowd: Developing crowd capital through crowdsourcing. Business Horizons. 58, 1 (2015), 77-85.

DOI:https://doi.org/10.1016/j.bushor.2014.09.0 05.

[17] Zytko, D., Ricken, S., Jones, Q. and Butler, B. 2019. Bowling Together Again : Facilitating the Initiation of Collective Action through Awareness of Others. HICSS'52 (2019). 